\title{
Chronic lymphocytic thyroiditis and BRAF V600E in papillary thyroid carcinoma
}

\author{
Seo Ki Kim', Jung-Woo Woo', Jun Ho Lee², Inhye Park', Jun-Ho Choe', Jung-Han Kim \\ and Jee Soo Kim \\ ${ }^{1}$ Division of Breast and Endocrine Surgery, Department of Surgery, Samsung Medical Center, \\ Sungkyunkwan University School of Medicine, 81 Irwon-ro, Gangnam-gu, Seoul 135-710, South Korea \\ ${ }^{2}$ Division of Breast and Endocrine Surgery, Department of Surgery, Samsung Changwon Hospital, \\ Sungkyunkwan University School of Medicine, Changwon, South Korea
}

\author{
Correspondence \\ should be addressed \\ to J S Kim; J-H Kim \\ Emails \\ jskim0126@skku.edu; \\ jinnee.kim@samsung.com
}

\begin{abstract}
It has been reported that papillary thyroid carcinoma (PTC) with chronic lymphocytic thyroiditis (CLT) is less associated with extrathyroidal extension (ETE), advanced tumor stage and lymph node (LN) metastasis. Other studies have suggested that concurrent CLT could antagonize PTC progression, even in BRAF-positive patients. Since the clinical significance of the BRAF mutation has been particularly associated with conventional PTC, the purpose of this study was to determine the clinical significance of CLT according to BRAF mutation status in conventional PTC patients. We retrospectively reviewed the medical records of 3332 conventional PTC patients who underwent total thyroidectomy with bilateral central neck dissection at the Thyroid Cancer Center of Samsung Medical Center between January 2008 and June 2015. In this study, the prevalence of BRAF mutation was significantly less frequent in conventional PTC patients with CLT $(76.9 \%$ vs $86.6 \%)$. CLT was an independent predictor for low prevalence of ETE in both BRAF-negative $(O R=0.662, P=0.023)$ and BRAF-positive $(\mathrm{OR}=0.817, P=0.027)$ conventional PTC patients. In addition, CLT was an independent predictor for low prevalence of CLNM in both BRAF-negative (OR=0.675, $P=0.044)$ and BRAF-positive ( $O R=0.817, P=0.030$ ) conventional PTC patients. In conclusion, BRAF mutation was significantly less frequent in conventional PTC patients with CLT. However, CLT was an independent predictor for less aggressiveness in conventional PTC patients regardless of BRAF mutation status.
\end{abstract}

\author{
Key Words \\ - BRAF mutation \\ - papillary thyroid carcinoma \\ - chronic lymphocytic \\ thyroiditis \\ - central lymph node \\ metastasis \\ - extrathyroidal extension
}

Endocrine-Related Cancer (2016) 23, 27-34

\section{Introduction}

With a rapidly increasing incidence worldwide, papillary thyroid carcinoma (PTC) represents the majority of thyroid cancer cases (Ahn \& Park 2009, Siegel et al. 2014). The recently discovered BRAF V600E mutation (hereafter referred to as the BRAF mutation) is the most potent activator of the mitogen-activated protein kinase pathway, which plays a central role in the regulation of cell growth, division and proliferation (Xing 2007). The BRAF mutation is found predominantly in PTC, particularly in the conventional and tall cell variants (Cohen et al. 2003). Numerous studies have demonstrated a strong association between the BRAF mutation and aggressive clinicopathological characteristics of PTC such as advanced stage, extrathyroidal extension (ETE), lymph

Published by Bioscientifica Ltd 
node (LN) metastasis and tumor recurrence (Kebebew et al. 2007, Lupi et al. 2007, Xing 2007). However, there were other studies that did not demonstrate the association between the BRAF mutation and aggressive clinicopathological characteristics of PTC (Lee et al. 2012a,b, Gouveia et al. 2013, Kim et al. 2015).

Chronic lymphocytic thyroiditis/Hashimoto's thyroiditis (hereafter referred to as CLT) is a femalepredominant autoimmune disease (Monaco 2012). Since the association between CLT and PTC was reported in 1955 (Dailey et al. 1955), many authors have reported that there is an increased risk of developing PTC in those with preexisting CLT (Zhang et al. 2012, Lee et al. 2013a). On the other hand, some investigators have reported that PTC with the coexistence of CLT is less associated with ETE, advanced stage, LN metastasis and recurrence (Loh et al. 1999, Kim et al. 2009a, Lang et al. 2014). Interestingly, in two previous studies focused on BRAF mutation status in patients with PTC with and without CLT in a Korean population, the BRAF mutation was found less frequently in subjects with CLT than without CLT ( $64 \%$ vs $90 \%$ and $72.9 \%$ vs $95.3 \%$ respectively) (Kim et al. 2005a, Kim et al. $2009 b$ ). Moreover, there was a study that suggested that concurrent CLT could antagonize PTC progression, even in BRAF-positive patients (Marotta et al. 2013).

On the basis of these results, we tried to determine the clinical significance of CLT according to BRAF mutation status. Since a previous study showed no association between the BRAF mutation and aggressive clinicopathological characteristics in the follicular variant of PTC (FV-PTC) (Proietti et al. 2010), we focused on a large-scale group of conventional PTC patients in particular, excluding other variants such as FV-PTC. Because a previous study suggested that concurrent CLT could antagonize PTC progression, even in BRAF-positive patients under a univariate analysis (Marotta et al. 2013), we designed a multivariate analysis regarding the relationship between CLT and BRAF mutation status in conventional PTC patients.

\section{Materials and methods}

\section{Patient selection}

This study was approved by the institutional review board at Samsung Medical Center. We retrospectively reviewed the medical records of 3332 pathologically-proven, conventional PTC patients who had undergone total thyroidectomy with bilateral central neck dissection (CND) at the Thyroid Cancer Center of the Samsung
Medical Center between January 2008 and June 2015. In accordance with the American Thyroid Association (ATA) management guidelines (American Thyroid Association Guidelines Taskforce on Thyroid N, Differentiated Thyroid C et al. 2009), CND was defined as a level VI dissection, including pre- and paratracheal nodes, the precricoid (delphian) node, the perithyroidal nodes and the $\mathrm{LN}$ along the recurrent laryngeal nerves. Patients with the following conditions were excluded from this study: age younger than 20 years or older than 80 years; PTC variants other than the conventional type; or the presence of lateral LN or distant metastasis.

\section{Histopathological examination with surgical specimens}

Surgical specimens were microscopically examined by two or more experienced pathologists and the following histopathologic factors were assessed: cell type of the main lesion, primary tumor size (measured as the longest diameter of the largest lesion), location, multiplicity, bilaterality, ETE, lymphovascular invasion, margin involvement, LN metastasis and the underlying conditions of the thyroid, such as CLT. The diagnosis of CLT was made on the presence of diffuse parenchymal infiltration by lymphocytes (particularly plasma B-cells), a germinal center formation, follicular destruction, Hurthle cell change and variable amounts of stromal fibrosis throughout the thyroid gland (Lloyd et al. 2002, Pearce et al. 2003, Cheng \& Bostwick 2011, Kakudo et al. 2011, Nikiforov et al. 2012). To distinguish bilaterality from multiplicity, we defined multiplicity as more than two lesions of conventional PTC in one lobe, regardless of the presence of bilaterality.

\section{BRAF mutation analysis}

BRAF mutation analysis was performed at the Molecular Diagnostics Laboratory of the Samsung Medical Center. DNA samples for molecular analysis were extracted from preoperative fine needle aspiration biopsy (FNAB) specimens or postoperative surgical specimens using QIAamp DNA mini-kits (Qiagen). Three distinct molecular methods were used for molecular analysis of the BRAF mutation. Direct sequencing after conventional PCR was performed in an ABI PRISM 3100 sequencer using BigDye Terminator cycle sequencing ready reaction kits (Applied Biosystems, Foster City, CA, USA). Dual Priming Oligonucleotide (DPO)-based allele-specific PCR (AS-PCR) using the Seeplex BRAF ACE detection system (Seegene, Seoul, Korea) with amplified products was analyzed using the

Published by Bioscientifica Ltd. 
ScreenTape system (Lab901 Ltd, Edinburgh, Scotland, UK). Mutant enrichment with $3^{\prime}$-modified oligonucleotides (MEMO)-based real-time PCR (RT-PCR) using Real-Q BRAF V600E detection kits (BioSewoom, Seoul, Korea) with amplified products was analyzed by BigDye Terminator Cycle Sequencing Kits v.3.1 (Applied Biosystems). DNA sequences from all three methods were compared with the normal BRAF gene exon 15 in the GenBank Database using sequence assembly software (Gene Codes Corp, Ann Arbor, MI, USA). When a thyroid nodule was evaluated using two or more molecular methods and yielded discordant results, the positive result was chosen for analysis.

\section{Statistical analysis}

Statistical analysis was performed using SPSS version 22.0 Software and statistically significant differences were defined as those with $P$ values of less than 0.05 . Continuous variables are presented as mean \pm s.D. and categorical variables are presented as the number of cases, with percentage (\%). For comparing the clinicopathological characteristics of conventional PTC patients, the $\chi^{2}$ test was used for categorical variables and Student's $t$-test was used for continuous variables. Univariate logistic regression analysis was used for calculating odds ratios for ETE and central LN metastasis (CLNM) according to BRAF mutation status and variables with a $P$ value $<0.05$ were included in the multivariate logistic regression analysis. Multivariate logistic regression analysis was conducted to determine the association between CLT and ETE and CLNM according to BRAF mutation status.

\section{Results}

\section{Association between CLT and clinicopathological characteristics of conventional PTC}

Among the 3332 pathologically proven conventional PTC patients, CLT was found in 1006 (30.2\%) patients (Table 1). Conventional PTC patients with CLT were significantly younger than patients without CLT (46.0 years vs 47.6 years, $P<0.001$ ), and tumor size was significantly smaller in patients with CLT than without CLT $(1.1 \mathrm{~cm}$ vs $1.2 \mathrm{~cm}, P=0.001)$. Female gender was significantly more frequent in patients with CLT $(90.7 \%$ vs $72.5 \%, P<0.001)$. However, ETE $(59.6 \%$ vs $67.1 \%$, $P<0.001)$, CLNM $(53.1 \%$ vs $61.3 \%, P<0.001)$ and positive BRAF mutation $(76.9 \%$ vs $86.6 \%, P<0.001)$ were significantly less frequent in patients with CLT.
Table 1 Association between CLT and clinicopathological characteristics of conventional PTC

\begin{tabular}{|c|c|c|c|}
\hline \multirow{3}{*}{$\begin{array}{l}\text { Clinicopathological } \\
\text { characteristics }\end{array}$} & \multicolumn{3}{|c|}{ All conventional PTC $(n=3332)$} \\
\hline & $\begin{array}{c}\mathrm{CLT}(-) \\
(n=2326)\end{array}$ & $\begin{array}{c}\mathrm{CLT}(+) \\
(n=1006)\end{array}$ & \\
\hline & No. (\%) & No. (\%) & $P$ value \\
\hline \multicolumn{4}{|l|}{ Age (years) } \\
\hline $\begin{array}{l}\text { Mean } \pm \text { S.D. } \\
<45\end{array}$ & $\begin{array}{r}47.6 \pm 11.9 \\
991(42.6)\end{array}$ & $\begin{array}{c}46.0 \pm 11.4 \\
482(47.9)\end{array}$ & $<0.001$ \\
\hline$\geq 45$ & $1335(57.4)$ & $524(52.1)$ & 0.005 \\
\hline \multicolumn{4}{|l|}{ Sex } \\
\hline Male & $639(27.5)$ & $94(9.3)$ & \\
\hline Female & $1687(72.5)$ & $912(90.7)$ & $<0.001$ \\
\hline \multicolumn{4}{|l|}{ Tumor size $(\mathrm{cm})$} \\
\hline $\begin{array}{l}\text { Mean } \pm \text { s.D. } \\
\leq 0.5\end{array}$ & $\begin{array}{l}1.2 \pm 0.8 \\
332(14.3)\end{array}$ & $\begin{array}{c}1.1 \pm 0.7 \\
155(15.4)\end{array}$ & 0.001 \\
\hline $0.5-1.0$ & $852(36.6)$ & $400(39.8)$ & \\
\hline $1.0-2.0$ & $868(37.3)$ & $362(36.0)$ & \\
\hline $2.0-4.0$ & $255(11.0)$ & $83(8.3)$ & \\
\hline$>4.0$ & $19(0.8)$ & $6(0.6)$ & 0.011 \\
\hline \multicolumn{4}{|l|}{ Multiplicity } \\
\hline Absent & 1648 (70.9) & $692(68.8)$ & \\
\hline Present & $678(29.1)$ & $314(31.2)$ & 0.232 \\
\hline \multicolumn{4}{|l|}{ Bilaterality } \\
\hline Absent & $1645(70.7)$ & $698(69.4)$ & \\
\hline Present & $681(29.3)$ & $308(30.6)$ & 0.437 \\
\hline \multicolumn{4}{|l|}{ ETE } \\
\hline Absent & 765 (32.9) & $406(40.4)$ & \\
\hline Present & $1561(67.1)$ & $600(59.6)$ & $<0.001$ \\
\hline \multicolumn{4}{|l|}{ CLNM } \\
\hline Absent & $899(38.7)$ & $472(46.9)$ & \\
\hline Present & $1427(61.3)$ & $534(53.1)$ & $<0.001$ \\
\hline \multicolumn{4}{|l|}{ BRAF } \\
\hline Negative & $311(13.4)$ & $232(23.1)$ & \\
\hline Positive & $2015(86.6)$ & 774 (76.9) & $<0.001$ \\
\hline
\end{tabular}

CLT, chronic lymphocytic thyroiditis; PTC, papillary thyroid carcinoma; ETE, extrathyroidal extension; CLNM, central lymph node metastasis.

Multiplicity and bilaterality were not significantly associated with CLT.

\section{Association between CLT and clinicopathological characteristics of conventional PTC according to BRAF mutation status}

BRAF mutations were found in 2789 (83.7\%) of the 3332 conventional PTC patients in this study (Table 2). Among the 543 BRAF-negative patients, CLT was seen in 232 (42.7\%) patients and among the 2789 BRAF-positive patients, CLT was seen in $774(27.8 \%)$ patients. The age of BRAF-negative patients was similar irrespective of the presence/absence of CLT (45.7 years vs 46.0 years, $P=0.822$ ). However, BRAF-positive patients with CLT were significantly younger than those without CLT (46.1 years vs 47.8 years, $P<0.001$ ). Female gender was

Published by Bioscientifica Ltd 
Table 2 Association between CLT and clinicopathological characteristics of conventional PTC according to BRAF mutation status

\begin{tabular}{|c|c|c|c|c|c|c|}
\hline \multirow{3}{*}{$\begin{array}{l}\text { Clinicopathological } \\
\text { characteristics }\end{array}$} & \multicolumn{3}{|c|}{ BRAF $(-)$ conventional PTC $(n=543)$} & \multicolumn{3}{|c|}{ BRAF $(+)$ conventional PTC $(n=2789)$} \\
\hline & $\operatorname{CLT}(-)(n=311)$ & $\operatorname{CLT}(+)(n=232)$ & & $\mathrm{CLT}(-)(n=2015)$ & $\mathrm{CLT}(+)(n=774)$ & \\
\hline & No. (\%) & No. (\%) & $P$ value & No. (\%) & No. (\%) & $P$ value \\
\hline \multicolumn{7}{|l|}{ Age (years) } \\
\hline Mean \pm s.D. & $46.0 \pm 11.7$ & $45.7 \pm 11.9$ & 0.822 & $47.8 \pm 11.9$ & $46.1 \pm 11.2$ & $<0.001$ \\
\hline$<45$ & $144(46.3)$ & $111(47.8)$ & & $847(42.0)$ & 371 (47.9) & \\
\hline$\geq 45$ & $167(53.7)$ & $121(52.2)$ & 0.722 & $1168(58.0)$ & $403(52.1)$ & 0.005 \\
\hline \multicolumn{7}{|l|}{ Sex } \\
\hline Male & $75(24.1)$ & $16(6.9)$ & & $564(28.0)$ & $78(10.1)$ & \\
\hline Female & $236(75.9)$ & $216(93.1)$ & $<0.001$ & $1451(72.0)$ & $696(89.9)$ & $<0.001$ \\
\hline \multicolumn{7}{|l|}{ Tumor size $(\mathrm{cm})$} \\
\hline Mean \pm s.D. & $1.3 \pm 1.0$ & $1.1 \pm 0.7$ & 0.021 & $1.2 \pm 0.8$ & $1.1 \pm 0.7$ & 0.015 \\
\hline$\leq 0.5$ & $54(17.4)$ & $46(19.8)$ & & $278(13.8)$ & $109(14.1)$ & \\
\hline $0.5-1.0$ & $108(34.7)$ & $84(36.2)$ & & 744 (36.9) & $316(40.8)$ & \\
\hline $1.0-2.0$ & 105 (33.8) & $80(34.5)$ & & $763(37.9)$ & $282(36.4)$ & \\
\hline $2.0-4.0$ & 40 (12.9) & $21(9.1)$ & & $215(10.7)$ & $62(8.0)$ & \\
\hline$>4.0$ & $4(1.3)$ & $1(0.4)$ & 0.145 & $15(0.7)$ & $5(0.6)$ & 0.048 \\
\hline \multicolumn{7}{|l|}{ Multiplicity } \\
\hline Absent & $223(71.7)$ & $173(74.6)$ & & 1425 (70.7) & $519(67.1)$ & \\
\hline Present & $88(28.3)$ & $59(25.4)$ & 0.457 & $590(29.3)$ & 255 (32.9) & 0.06 \\
\hline \multicolumn{7}{|l|}{ Bilaterality } \\
\hline Absent & $240(77.2)$ & 178 (76.7) & & 1405 (69.7) & $520(67.2)$ & \\
\hline Present & $71(22.8)$ & $54(23.3)$ & 0.903 & $610(30.3)$ & $254(32.8)$ & 0.193 \\
\hline \multicolumn{7}{|l|}{ ETE } \\
\hline Absent & $120(38.6)$ & $116(50.0)$ & & $645(32.0)$ & $290(37.5)$ & \\
\hline Present & $191(61.4)$ & $116(50.0)$ & 0.008 & $1370(68.0)$ & $484(62.5)$ & 0.006 \\
\hline \multicolumn{7}{|l|}{ CLNM } \\
\hline Absent & 118 (37.9) & $121(52.2)$ & & 781 (38.8) & $351(45.3)$ & \\
\hline Present & $193(62.1)$ & $111(47.8)$ & 0.001 & $1234(61.2)$ & $423(54.7)$ & 0.002 \\
\hline
\end{tabular}

CLT, chronic lymphocytic thyroiditis; PTC, papillary thyroid carcinoma; ETE, extrathyroidal extension; CLNM, central lymph node metastasis.

significantly more frequent in both BRAF-negative $(93.1 \%$ vs $75.9 \%, P<0.001)$ and BRAF-positive (89.9\% vs $72.0 \%$, $P<0.001)$ patients with CLT. Tumor size was significantly smaller in patients with CLT than without CLT for both BRAF-negative $(1.1 \mathrm{~cm}$ vs $1.3 \mathrm{~cm}, P=0.021)$ and BRAFpositive ( $1.1 \mathrm{~cm}$ vs $1.2 \mathrm{~cm}, P=0.015)$ mutation status. ETE (BRAF-negative, $50.0 \%$ vs $61.4 \%, P=0.008$; BRAF-positive, $62.5 \%$ vs $68.0 \%, P=0.006$ ) and CLNM (BRAF-negative, $47.8 \%$ vs $62.1 \%, P=0.001$; BRAF-positive, $54.7 \%$ vs $61.2 \%$, $P=0.002$ ) were consistently less frequent in patients with
CLT regardless of BRAF mutation status. Multiplicity and bilaterality were not associated with CLT in either BRAF-negative or BRAF-positive patients.

\section{CLT was an independent predictor for low prevalence of ETE in both BRAF-negative and BRAF-positive conventional PTC patients}

As seen in Table 2, ETE was significantly less frequent in conventional PTC patients with CLT (Tables 3 and 4).

Table 3 Association between ETE and clinicopathological characteristics of BRAF-negative conventional PTC

\begin{tabular}{l} 
Clinicopathological characteristics \\
\hline Age (per 10 years) \\
Female \\
Tumor size (per $0.1 \mathrm{~cm}$ ) \\
Multiplicity \\
Bilaterality \\
CLT
\end{tabular}

\begin{tabular}{|c|c|}
\hline \multicolumn{2}{|c|}{ Univariate analysis } \\
\hline OR $(95 \% \mathrm{Cl})$ for $\mathrm{ETE}$ & $P$ value \\
\hline $0.822(0.714-0.947)$ & 0.007 \\
\hline $0.659(0.413-1.053)$ & 0.080 \\
\hline $1.961(1.513-2.543)$ & $<0.001$ \\
\hline $1.586(1.072-2.346)$ & 0.021 \\
\hline $1.311(0.871-1.973)$ & 0.193 \\
\hline $0.628(0.445-0.886)$ & 0.008 \\
\hline
\end{tabular}

\begin{tabular}{ccc}
\multicolumn{2}{c}{ Multivariate analysis } \\
\hline OR $(95 \% \mathrm{Cl})$ for ETE & & $P$ value \\
\hline $0.875(0.753-1.017)$ & & 0.081 \\
NA & & NA \\
$1.818(1.394-2.371)$ & & $<0.001$ \\
$1.509(1.005-2.256)$ & & 0.048 \\
NA & & NA \\
$0.662(0.464-0.944)$ & 0.023 \\
\hline
\end{tabular}

ETE, extrathyroidal extension; PTC, papillary thyroid carcinoma; OR, odds ratio; CLT, chronic lymphocytic thyroiditis. 
Table 4 Association between ETE and clinicopathological characteristics of BRAF-positive conventional PTC

\begin{tabular}{l} 
Clinicopathological characteristics \\
\hline Age (per 10 years) \\
Female \\
Tumor size (per $0.1 \mathrm{~cm}$ ) \\
Multiplicity \\
Bilaterality \\
CLT
\end{tabular}

\begin{tabular}{|c|c|}
\hline \multicolumn{2}{|c|}{ Univariate analysis } \\
\hline OR $(95 \% \mathrm{Cl})$ for $\mathrm{ETE}$ & $P$ value \\
\hline $0.885(0.829-0.945)$ & $<0.001$ \\
\hline $1.025(0.851-1.235)$ & 0.792 \\
\hline $2.088(1.809-2.410)$ & $<0.001$ \\
\hline $1.681(1.404-2.011)$ & $<0.001$ \\
\hline $1.357(1.140-1.615)$ & 0.001 \\
\hline $0.786(0.661-0.934)$ & 0.006 \\
\hline
\end{tabular}

\begin{tabular}{|c|c|}
\hline \multicolumn{2}{|c|}{ Multivariate analysis } \\
\hline OR $(95 \% \mathrm{Cl})$ for $\mathrm{ETE}$ & $P$ value \\
\hline $0.865(0.807-0.928)$ & $<0.001$ \\
\hline NA & NA \\
\hline $2.162(1.870-2.501)$ & $<0.001$ \\
\hline $1.695(1.398-2.053)$ & $<0.001$ \\
\hline $1.146(0.950-1.383)$ & 0.155 \\
\hline $0.817(0.683-0.977)$ & 0.027 \\
\hline
\end{tabular}

ETE, extrathyroidal extension; PTC, papillary thyroid carcinoma; OR, odds ratio; CLT, chronic lymphocytic thyroiditis.

Therefore, we analyzed whether CLT could be an independent predictor for low prevalence of ETE. As seen in Tables 3 and 4, CLT was an independent predictor for low prevalence of ETE in both BRAF-negative ( $\mathrm{OR}=0.662$, $P=0.023)$ and BRAF-positive $(\mathrm{OR}=0.817, P=0.027)$ patients. In BRAF-negative patients, tumor size per $0.1 \mathrm{~cm}(\mathrm{OR}=1.818, P<0.001)$ and multiplicity $(\mathrm{OR}=$ 1.509, $P=0.048$ ) were independent predictors for high prevalence of ETE. In BRAF-positive conventional PTC patients, age per 10 years $(\mathrm{OR}=0.865, P<0.001)$ was an independent predictor for low prevalence of ETE. Tumor size per $0.1 \mathrm{~cm}(\mathrm{OR}=2.088, P<0.001)$ and multiplicity $(\mathrm{OR}=1.695, P<0.001)$ were independent predictors for high prevalence of ETE.

\section{CLT was an independent predictor for low prevalence of CLNM in both BRAF-negative and BRAF-positive conven- tional PTC patients}

As seen in Table 2, CLNM was also significantly less frequent in conventional PTC patients with CLT (Tables 5 and 6). We investigated whether CLT could be an independent predictor for low prevalence of CLNM. As seen in Tables 5 and 6, CLT was an independent predictor for low prevalence of CLNM in both BRAF-negative $(\mathrm{OR}=$ $0.675, P=0.044)$ and BRAF-positive $(\mathrm{OR}=0.817, P=0.030)$ patients. In BRAF-negative patients, age per 10 years $(\mathrm{OR}=$ $0.757, P=0.001)$ and female gender $(\mathrm{OR}=0.481, P=0.009)$ were independent predictors for low prevalence of CLNM. Tumor size per $0.1 \mathrm{~cm}(\mathrm{OR}=1.680, P<0.001)$, multiplicity $(\mathrm{OR}=2.336, P<0.001)$ and ETE $(\mathrm{OR}=2.401, P<0.001)$ were independent predictors for high prevalence of CLNM. In BRAF-positive conventional PTC patients, age per 10 years $(\mathrm{OR}=0.652, P<0.001)$ and female gender $(\mathrm{OR}=0.482, P<0.001)$ were independent predictors for low prevalence of CLNM. Tumor size per $0.1 \mathrm{~cm}$ $(\mathrm{OR}=1.965, P<0.001)$, multiplicity $(\mathrm{OR}=1.280, P=0.006)$ and ETE $(\mathrm{OR}=1.478, P<0.001)$ were independent predictors for high prevalence of CLNM.

\section{Discussion}

The purpose of this study was to determine whether CLT could be an independent predictor for aggressiveness in conventional PTC patients according to BRAF mutation status. Although a previous study suggested that concurrent CLT could antagonize PTC progression even in BRAF-positive patients (Marotta et al. 2013), the analysis was univariate and evaluated only a small number of exclusively BRAF-positive patients. In this study, we performed a multivariate analysis and revealed that CLT was an independent predictor for the low prevalence of

Table 5 Association between CLNM and clinicopathological characteristics of BRAF-negative conventional PTC

\begin{tabular}{l} 
Clinicopathological characteristics \\
\hline Age (per 10 years) \\
Female \\
Tumor size (per $0.1 \mathrm{~cm}$ ) \\
Multiplicity \\
Bilaterality \\
ETE \\
CLT
\end{tabular}

\begin{tabular}{lr}
\hline \multicolumn{2}{c}{ Univariate analysis } \\
\hline OR $(95 \%$ Cl) for CLNM & \multicolumn{1}{c}{$P$ value } \\
\hline $0.725(0.627-0.838)$ & $<0.001$ \\
$0.395(0.239-0.652)$ & $<0.001$ \\
$2.165(1.651-2.840)$ & $<0.001$ \\
$2.475(1.645-3.724)$ & $<0.001$ \\
$0.846(0.567-1.263)$ & 0.414 \\
$3.165(2.222-4.509)$ & $<0.001$ \\
$0.561(0.397-0.792)$ & 0.001 \\
\hline
\end{tabular}

\begin{tabular}{ccc}
\multicolumn{2}{c}{ Multivariate analysis } \\
\hline OR $(95 \% \mathrm{Cl})$ for CLNM & $P$ value \\
\cline { 1 - 1 } & & 0.001 \\
$0.481(0.278-0.831)$ & & 0.009 \\
$1.680(1.266-2.229)$ & & $<0.001$ \\
$2.336(1.499-3.642)$ & & $<0.001$ \\
NA & & NA \\
$2.401(1.642-3.512)$ & & 0.001 \\
$0.675(0.460-0.989)$ & 0.044 \\
\hline
\end{tabular}

CLNM, central lymph node metastasis; PTC, papillary thyroid carcinoma; OR, odds ratio; CLT, chronic lymphocytic thyroiditis.

$$
\begin{aligned}
& \text { http://erc.endocrinology-journals.org } \\
& \begin{array}{l}
2016 \text { Society for Endocrinology } \\
\text { DOI: } 10.1530 / \text { ERC-15-0408 }
\end{array}
\end{aligned}
$$

Published by Bioscientifica Ltd 
Table 6 Association between CLNM and clinicopathological characteristics of BRAF-positive conventional PTC

\begin{tabular}{l} 
Clinicopathological characteristics \\
\hline Age (per 10 years) \\
Female \\
Tumor size (per $0.1 \mathrm{~cm}$ ) \\
Multiplicity \\
Bilaterality \\
ETE \\
CLT
\end{tabular}

\begin{tabular}{lr}
\hline \multicolumn{2}{c}{ Univariate analysis } \\
\hline OR $(95 \%$ Cl) for CLNM & \multicolumn{1}{c}{$P$ value } \\
\hline $0.674(0.631-0.721)$ & $<0.001$ \\
$0.435(0.358-0.529)$ & $<0.001$ \\
$2.134(1.866-2.440)$ & $<0.001$ \\
$1.211(1.026-1.430)$ & 0.024 \\
$1.139(0.967-1.343)$ & 0.119 \\
$1.626(1.387-1.907)$ & $<0.001$ \\
$0.763(0.645-0.902)$ & 0.002 \\
\hline
\end{tabular}

\begin{tabular}{ccc}
\hline \multicolumn{2}{c}{ Multivariate analysis } \\
\hline OR $(95 \% \mathrm{Cl})$ for CLNM & $P$ value \\
\hline $0.652(0.607-0.700)$ & & $<0.001$ \\
$0.482(0.391-0.594)$ & & $<0.001$ \\
$1.965(1.709-2.260)$ & & $<0.001$ \\
$1.280(1.072-1.530)$ & & 0.006 \\
NA & NA \\
$1.478(1.240-1.761)$ & $<0.001$ \\
$0.817(0.681-0.981)$ & 0.030 \\
\hline
\end{tabular}

CLNM, central lymph node metastasis; PTC, papillary thyroid carcinoma; OR, odds ratio; CLT, chronic lymphocytic thyroiditis.

ETE and CLNM in both BRAF-positive and BRAF-negative conventional PTC patients.

Classically, CLT frequently occurs in females (F:M= 10:1) (Monaco 2012), and we consistently found a strong association of CLT with female gender, regardless of BRAF mutation status. It has been suggested that concurrent CLT is significantly associated with a lower frequency of BRAF mutations (Kim et al. 2005a, Kim et al. 2009b), and we also observed that the BRAF mutation was significantly less frequent in conventional PTC patients with CLT (76.9\% vs $86.6 \%, P<0.001$ ). A recent study proposed that the prevalence of the BRAF mutation in patients with CLT has been underestimated by a dilution effect on the mutated alleles of infiltrating lymphocytes, which carry WT BRAF (Guerra et al. 2012). Further investigations are needed to elucidate the association between CLT and the BRAF mutation.

In all conventional PTC patients regardless of BRAF mutation status, CLT was significantly associated with a low prevalence of aggressive clinicopathological characteristics, including tumor size, ETE and CLNM (Tables 1 and 2). Furthermore, from the multivariate analysis (Tables 3 and 4), CLT was an independent predictor for the low prevalence of conventional PTC in both BRAFnegative and BRAF-positive patients. These results support the hypothesis that the coexistence of CLT counteracts tumor progression and recurrence in PTC (Loh et al. 1999, Kim et al. 2009a, Lang et al. 2014). Furthermore, there were previous studies that did not demonstrate the association between BRAF mutation and aggressive clinicopathological characteristics of PTC (Lee et al. 2012a,b, Gouveia et al. 2013, Kim et al. 2015). These studies could explain why the impact of CLT was not different according to BRAF mutation status.

Particularly, CLT can be detected in three ways preoperatively. First, FNAB is a sensitive and specific tool for the detection of CLT (Carson et al. 1996, Kini \& Grossl 1997, MacDonald \& Yazdi 2011). Secondly, diffuse parenchymal heteroechogenicity in US is commonly regarded as a strong indicator for CLT (Gutekunst et al. 1989, Marcocci et al. 1991, Rago et al. 2001). Thirdly, the presence of thyroid autoantibodies, typically anti-thyroid peroxidase antibodies in the serum, however, seronegative CLT is also possible (Grani et al. 2015). Based on results from previous work (Loh et al. 1999, Kim et al. 2009a, Lang et al. 2014) and this study, preoperative recognition of CLT by careful reviewing of FNAB, US and serology can be valuable for risk stratification in conventional PTC patients.

In agreement with previous studies, we found that young age (Roh et al. 2011, Kim et al. 2015), male gender (Lang et al. 2014, Kim et al. 2015), large tumor size (Roh et al. 2011, Joo et al. 2012, Lang et al. 2014, Kim et al. 2015), multiplicity (Lang et al. 2014, Kim et al. 2015) and ETE (Roh et al. 2011, Joo et al. 2012, Lang et al. 2014, Kim et al. 2015) were independent predictors for high prevalence of CLNM regardless of BRAF mutation status, and bilaterality (Lang et al. 2014, Kim et al. 2015) was not. Primarily, for clear analysis, we excluded conventional PTC patients with tumor size $>4.0 \mathrm{~cm}$. Because there were only 25 patients who met the inclusion criteria of this study and the size variation of the 25 patients was very wide, from 4.1 to $8.0 \mathrm{~cm}$. However, our results and conclusion were not changed whether 25 conventional PTC patients with tumor size $>4.0 \mathrm{~cm}$ were included or excluded. Therefore, we included 25 conventional PTC patients with tumor size $>4.0 \mathrm{~cm}$

This study had several limitations. First, since the study had a retrospective design, patient information was not fully collected. Further prospective studies might be required to clarify the relationship between PTC and CLT. Secondly, since this study was conducted in a

Published by Bioscientifica Ltd. 
BRAF-prevalent area (Kim et al. 2004, Kim et al. 2005b), the results may not be applicable to other populations. Thirdly, since we enrolled only conventional PTC patients, the results of this study cannot be applied to other types of thyroid cancers or other variants of PTC. Fourthly, this study included conventional PTC patients who underwent total thyroidectomy with bilateral CND. Total thyroidectomy was performed according to ATA management guidelines (American Thyroid Association Guidelines Taskforce on Thyroid et al. 2009) when primary tumor size $>1 \mathrm{~cm}$, multifocality, bilaterality, ETE, or abnormal lymphadenopathy was detected during preoperative or intraoperative examination. Furthermore, therapeutic CND was performed when abnormal lymphadenopathy was detected during preoperative or intraoperative examination, and prophylactic CND was performed on PTC patients with clinically uninvolved central neck LNs, in particular for advanced primary tumors $\left(T_{3} / T_{4}\right)$. Therefore, the selection of cases was possibly biased toward a high-risk group. Finally, three distinct types of molecular methods and two distinct types of specimens were used for BRAF mutation analysis. We did not perform BRAF mutation analysis as a routine preoperative examination, and molecular methods have evolved over the years since March 2008. This variability may have introduced inconsistencies in the results of BRAF mutation testing. Although we performed BRAF mutation analysis with both FNAB specimens and surgical specimens, numerous studies have demonstrated that BRAF mutation analysis can be performed readily and reliably using solely FNAB specimens preoperatively (Chung et al. 2006, Jin et al. 2006).

In conclusion, BRAF mutation was significantly less frequent in conventional PTC patients with CLT. However, CLT was an independent predictor for less aggressiveness in conventional PTC patients regardless of BRAF mutation status. Since there have been only a few studies regarding this topic, further investigations are needed to elucidate the relationship between BRAF mutations and CLT.

\section{Declaration of interest}

The authors declare that there is no conflict of interest that could be perceived as prejudicing the impartiality of the research reported.

\section{Funding}

This research did not receive any specific grant from any funding agency in the public, commercial or not-for-profit sector.
Author contribution statement

S K Kim, J-W Woo, J H Lee and I Park were involved in the review of literature, acquisition of data and drafting and completing the manuscript. S K Kim, J-H Choe, J-H Kim and J S Kim conceived the study, participated in the co-ordination and the acquisition of data and helped to draft the manuscript. All authors read and approved the final manuscript.

\section{References}

Ahn HY \& Park YJ 2009 Incidence and clinical characteristics of thyroid cancer in Korea. Korean Journal of Medical Education 77 537-542.

American Thyroid Association Guidelines Taskforce on Thyroid N and Differentiated Thyroid C , Cooper DS, Doherty GM, Haugen BR, Kloos RT, Lee SL, Mandel SJ, Mazzaferri EL, McIver B \& Pacini F 2009 Revised American Thyroid Association management guidelines for patients with thyroid nodules and differentiated thyroid cancer. Thyroid 19 1167-1214. (doi:10.1089/thy.2009.0110)

Carson HJ, Castelli MJ \& Gattuso P 1996 Incidence of neoplasia in Hashimoto's thyroiditis: a fine needle aspiration study. Diagnostic Cytopathology 14 38-42. (doi:10.1002/(SICI)1097-0339(199602)14:1 $<38$ ::AID-DC8 > 3.0.CO;2-R)

Cheng L \& Bostwick DG 2011 Essentials of Anatomic Pathology, p910. New York, NY, USA: Springer.

Chung KW, Yang SK, Lee GK, Kim EY, Kwon S, Lee SH, Park DJ, Lee HS, Cho BY, Lee ES et al. 2006 Detection of BRAFV600E mutation on fine needle aspiration specimens of thyroid nodule refines cyto-pathology diagnosis, especially in BRAFV600E mutationae-prevalent area. Clinical Endocrinology 65 660-666. (doi:10.1111/j.1365-2265.2006.02646.x)

Cohen Y, Xing M, Mambo E, Guo Z, Wu G, Trink B, Beller U, Westra WH, Ladenson PW \& Sidransky D 2003 BRAF mutation in papillary thyroid carcinoma. Journal of the National Cancer Institute 95 625-627. (doi:10.1093/jnci/95.8.625)

Dailey ME, Lindsay S \& Skahen R 1955 Relation of thyroid neoplasms to Hashimoto disease of the thyroid gland. A.M.A. Archives of Surgery $\mathbf{7 0}$ 291-297. (doi:10.1001/archsurg.1955.01270080137023)

Gouveia C, Can NT, Bostrom A, Grenert JP, van Zante A \& Orloff LA 2013 Lack of association of BRAF mutation with negative prognostic indicators in papillary thyroid carcinoma: the University of California, San Francisco, experience. JAMA Otolaryngology - Head \& Neck Surgery 139 1164-1170. (doi:10.1001/jamaoto.2013.4501)

Grani G, Carbotta G, Nesca A, D'Alessandri M, Vitale M, Del Sordo M \& Fumarola A 2015 A comprehensive score to diagnose Hashimoto's thyroiditis: a proposal. Endocrine 49 361-365. (doi:10.1007/s12020014-0441-5)

Guerra A, Sapio MR, Marotta V, Campanile E, Rossi S, Forno I, Fugazzola L, Budillon A, Moccia T, enzi G et al. 2012 The primary occurrence of $\mathrm{BRAF}(\mathrm{V} 600 \mathrm{E})$ is a rare clonal event in papillary thyroid carcinoma. Journal of Clinical Endocrinology and Metabolism 97 517-524. (doi:10.1210/jc.2011-0618)

Gutekunst R, Hafermann W, Mansky T \& Scriba PC 1989 Ultrasonography related to clinical and laboratory findings in lymphocytic thyroiditis. Acta Endocrinologica 121 129-135.

Jin L, Sebo TJ, Nakamura N, Qian X, Oliveira A, Majerus JA, Johnson MR \& Lloyd RV 2006 BRAF mutation analysis in fine needle aspiration (FNA) cytology of the thyroid. Diagnostic Molecular Pathology 15 136-143. (doi:10.1097/01.pdm.0000213461.53021.84)

Joo JY, Park JY, Yoon YH, Choi B, Kim JM, Jo YS, Shong M \& Koo BS 2012 Prediction of occult central lymph node metastasis in papillary thyroid carcinoma by preoperative BRAF analysis using fine-needle aspiration biopsy: a prospective study. Journal of Clinical Endocrinology and Metabolism 97 3996-4003. (doi:10.1210/jc.2012-2444)

Published by Bioscientifica Ltd. 
Kakudo K, Li Y, Hirokawa M \& Ozaki T 2011 Diagnosis of Hashimoto's thyroiditis and IgG4-related sclerosing disease. Pathology International 61 175-183. (doi:10.1111/j.1440-1827.2011.02661.x)

Kebebew E, Weng J, Bauer J, Ranvier G, Clark OH, Duh QY, Shibru D, Bastian B \& Griffin A 2007 The prevalence and prognostic value of BRAF mutation in thyroid cancer. Annals of Surgery 246 466-470; discussion 470-461. (doi:10.1097/SLA.0b013e318148563d)

Kim KH, Kang DW, Kim SH, Seong IO \& Kang DY 2004 Mutations of the BRAF gene in papillary thyroid carcinoma in a Korean population. Yonsei Medical Journal 45 818-821. (doi:10.3349/ymj.2004.45.5.818)

Kim KH, Suh KS, Kang DW \& Kang DY 2005a Mutations of the BRAF gene in papillary thyroid carcinoma and in Hashimoto's thyroiditis. Pathology International 55 540-545. (doi:10.1111/j.1440-1827.2005.01866.x)

Kim TY, Kim WB, Song JY, Rhee YS, Gong G, Cho YM, Kim SY, Kim SC, Hong SJ \& Shong YK 2005b The BRAF mutation is not associated with poor prognostic factors in Korean patients with conventional papillary thyroid microcarcinoma. Clinical Endocrinology 63 588-593. (doi:10.1111/j.1365-2265.2005.02389.x)

Kim EY, Kim WG, Kim WB, Kim TY, Kim JM, Ryu JS, Hong SJ, Gong G \& Shong YK 2009a Coexistence of chronic lymphocytic thyroiditis is associated with lower recurrence rates in patients with papillary thyroid carcinoma. Clinical Endocrinology 71 581-586. (doi:10.1111/ j.1365-2265.2009.03537.x)

Kim SK, Song KH, Lim SD, Lim YC, Yoo YB, Kim JS \& Hwang TS $2009 b$ Clinical and pathological features and the BRAF(V600E) mutation in patients with papillary thyroid carcinoma with and without concurrent Hashimoto thyroiditis. Thyroid 19 137-141. (doi:10.1089/thy.2008.0144)

Kim SK, Woo JW, Lee JH, Park I, Choe JH, Kim JH \& Kim JS 2015 Role of BRAF V600E mutation as an indicator of the extent of thyroidectomy and lymph node dissection in conventional papillary thyroid carcinoma. Surgery [in press]. (doi:10.1016/j.surg.2015.05.016)

Kini SR \& Grossl N 1997 Guides to clinical aspiration biopsy: thyroid. Archives of Pathology \& Laboratory Medicine 121 1115-1115.

Lang BH, Chai YJ, Cowling BJ, Min HS, Lee KE \& Youn YK 2014 Is BRAFV600E mutation a marker for central nodal metastasis in small papillary thyroid carcinoma? Endocrine-Related Cancer 21 285-295. (doi:10.1530/ERC-13-0291)

Lee KC, Li C, Schneider EB, Wang Y, Somervell H, Krafft M, Umbricht CB \& Zeiger MA $2012 a$ Is BRAF mutation associated with lymph node metastasis in patients with papillary thyroid cancer? Surgery $\mathbf{1 5 2}$ 977-983. (doi:10.1016/j.surg.2012.08.019)

Lee ST, Kim SW, Ki CS, Jang JH, Shin JH, Oh YL, Kim JW \& Chung JH $2012 b$ Clinical implication of highly sensitive detection of the BRAF V600E mutation in fine-needle aspirations of thyroid nodules: a comparative analysis of three molecular assays in 4585 consecutive cases in a BRAF V600E mutation-prevalent area. Journal of Clinical Endocrinology and Metabolism 97 2299-2306. (doi:10.1210/jc.2011-3135)

Lee JH, Kim Y, Choi JW \& Kim YS 2013a The association between papillary thyroid carcinoma and histologically proven Hashimoto's thyroiditis: a meta-analysis. European Journal of Endocrinology 168 343-349. (doi:10.1530/EJE-12-0903)

Lloyd RV, Douglas BR \& Young WF 2002 Endocrine Diseases. Washington DC, USA: American Registry of Pathology.
Loh KC, Greenspan FS, Dong F, Miller TR \& Yeo PP 1999 Influence of lymphocytic thyroiditis on the prognostic outcome of patients with papillary thyroid carcinoma. Journal of Clinical Endocrinology and Metabolism 84 458-463. (doi:10.1210/jcem.84.2.5443)

Lupi C, Giannini R, Ugolini C, Proietti A, Berti P, Minuto M, Materazzi G, Elisei R, Santoro M, iccoli P et al. 2007 Association of BRAF V600E mutation with poor clinicopathological outcomes in 500 consecutive cases of papillary thyroid carcinoma. Journal of Clinical Endocrinology and Metabolism 92 4085-4090. (doi:10.1210/jc.2007-1179)

MacDonald L \& Yazdi HM 2011 Fine needle aspiration biopsy of Hashimoto's thyroiditis. Acta Cytologica 43 400-406. (doi:10.1159/ 000331088)

Marcocci C, Vitti P, Cetani F, Catalano F, Concetti R \& Pinchera A 1991 Thyroid ultrasonography helps to identify patients with diffuse lymphocytic thyroiditis who are prone to develop hypothyroidism. Journal of Clinical Endocrinology and Metabolism 72 209-213. (doi:10.1210/jcem-72-1-209)

Marotta V, Guerra A, Zatelli MC, Uberti ED, Di Stasi V, Faggiano A, Colao A \& Vitale M 2013 BRAF mutation positive papillary thyroid carcinoma is less advanced when Hashimoto's thyroiditis lymphocytic infiltration is present. Clinical Endocrinology 79 733-738. (doi:10.1111/cen.12194)

Monaco F 2012 Thyroid Diseases. Boca Raton, FL: Taylor, Francis/CRC Press.

Nikiforov YE, Biddinger PW \& Thompson LD 2012 Diagnostic Pathology and Molecular Genetics of the Thyroid: A Comprehensive Guide for Practicing Thyroid Pathology, pp51-53. Philadelphia, PA, USA: Lippincott Williams \& Wilkins.

Pearce EN, Farwell AP \& Braverman LE 2003 Thyroiditis. New England Journal of Medicine 348 2646-2655. (doi:10.1056/NEJMra021194)

Proietti A, Giannini R, Ugolini C, Miccoli M, Fontanini G, Di Coscio G, Romani R, Berti P, Miccoli P \& Basolo F 2010 BRAF status of follicular variant of papillary thyroid carcinoma and its relationship to its clinical and cytological features. Thyroid 20 1263-1270. (doi:10.1089/thy.2009. 0283)

Rago T, Chiovato L, Grasso L, Pinchera A \& Vitti P 2001 Thyroid ultrasonography as a tool for detecting thyroid autoimmune diseases and predicting thyroid dsfunction in apparently healthy subjects. Journal of Endocrinological Investigation 24 763-769. (doi:10.1007/ BF03343925)

Roh JL, Kim JM \& Park CI 2011 Central lymph node metastasis of unilateral papillary thyroid carcinoma: patterns and factors predictive of nodal metastasis, morbidity, and recurrence. Annals of Surgical Oncology 18 2245-2250. (doi:10.1245/s10434-011-1600-z)

Siegel R, Ma J, Zou Z \& Jemal A 2014 Cancer statistics, 2014. CA: A Cancer Journal for Clinicians 64 9-29. (doi:10.3322/caac.21208)

Xing M 2007 BRAF mutation in papillary thyroid cancer: pathogenic role, molecular bases, and clinical implications. Endocrine Reviews $\mathbf{2 8}$ 742-762. (doi:10.1210/er.2007-0007)

Zhang L, Li H, Ji QH, Zhu YX, Wang ZY, Wang Y, Huang CP, Shen Q, Li DS $\&$ Wu Y 2012 The clinical features of papillary thyroid cancer in Hashimoto's thyroiditis patients from an area with a high prevalence of Hashimoto's disease. BMC Cancer 12 610. (doi:10.1186/1471-240712-610)

Received in final form 12 October 2015

Accepted 16 October 2015

Made available online as an Accepted Preprint

16 October 2015 http://erc.endocrinology-journals.org DOI: 10.1530/ERC-15-0408
(C) 2016 Society for Endocrinology Printed in Great Britain
Published by Bioscientifica Ltd 